University of Nebraska - Lincoln

DigitalCommons@University of Nebraska - Lincoln

June 2002

\title{
Too Many of a Good Thing? The Effects of Multiple Motivations on Stress, Cost, Fulfillment, and Satisfaction
}

\author{
Marc T. Kiviniemi \\ University of Nebraska-Lincoln, mtk8@buffalo.edu \\ Mark Snyder \\ University of Minnesota, msnyder@umn.edu \\ Allen M. Omoto \\ Claremont Graduate University, Allen.Omoto@cgu.edu
}

Follow this and additional works at: https://digitalcommons.unl.edu/psychfacpub

Part of the Psychiatry and Psychology Commons

Kiviniemi, Marc T.; Snyder, Mark; and Omoto, Allen M., "Too Many of a Good Thing? The Effects of Multiple Motivations on Stress, Cost, Fulfillment, and Satisfaction " (2002). Faculty Publications, Department of Psychology. 12.

https://digitalcommons.unl.edu/psychfacpub/12

This Article is brought to you for free and open access by the Psychology, Department of at DigitalCommons@University of Nebraska - Lincoln. It has been accepted for inclusion in Faculty Publications, Department of Psychology by an authorized administrator of DigitalCommons@University of Nebraska - Lincoln. 


\section{Too Many of a Good Thing? The Effects of Multiple Motivations on Stress, Cost, Fulfillment, and Satisfaction}

\author{
Marc T. Kiviniemi \\ University of Nebraska-Lincoln
}

Mark Snyder

University of Minnesota

\author{
Allen M. Omoto \\ Claremont Graduate University
}

Individuals engage in behaviors to satisfy motivations and can engage in the same behavior to satisfy a variety of different motivations. Previous research has examined how differences in the overall amount of motivation influence outcomes but has not addressed how differences in the number of conceptually distinct motivations one has for a particular action influence outcomes. In two longitudinal field studies, individuals with more than one motivation for volunteering experienced greater negative outcomes than did those who volunteered to satisfy a single motivation. A laboratory study manipulated the number of motivations individuals had for engaging in a volunteer activity. Individuals with two motivations reported greater negative outcomes than did those with one motivation. The importance of these findings for understanding the linkages of motivation and action in self-regulated behaviors is discussed.

\footnotetext{
C
} onsider the following scenarios: First, consider the situation of a middle-age adult returning to college to earn an undergraduate degree. She is returning to the university to gain skills to advance her career. At the same time, she feels good about herself when she is learning and wants to enhance that feeling, and she is further guided by her belief in the inherent value of educational endeavors. Next, consider a teenager doing volunteer work at a local elementary school. Her guidance counselor suggested that volunteer service would look good on college applications. In addition, it enables her to feel she is giving something back to her community and it gives her an opportunity to spend time with friends who also volunteer.
These scenarios share two common themes. First, each person is engaging in an activity to satisfy personal needs and desires. Second, each individual is engaging in the activity in the service of not one but multiple motivations. We will address each of these common themes, beginning with the motivated nature of the activities, because that is the theme that has received the largest share of previous research attention. We will then turn to the second theme, the multiply motivated nature of the activities, which is the focus of this article. Individuals seek to fulfill personal motivational needs by selecting and engaging in behaviors that they believe will enable them to satisfy their needs, and the motives guiding individuals in a particular situation play a significant role in organizing their ongoing behavior (Cantor,

\footnotetext{
Authors' Note: This research and the preparation of this article were supported by grants from the National Institute of Mental Health to Mark Snyder and Allen M. Omoto. Marc T. Kiviniemi was supported by a University of Minnesota Doctoral Dissertation Fellowship and by a University of Nebraska-Lincoln Faculty Fellowship during the preparation of this article. The assistance of Stephen A. Asche and A. Lauren Crain in the collection of data for Studies 1 and 2 and of Alyssa Clevinger, Katherine Nelson, and Zachary Remus for Study 3 data collection is gratefully acknowledged, as are the comments of Gustavo Carlo, Jennifer S. Hunt, and two anonymous reviewers on an earlier draft of this article. Finally, we wish to thank the AIDS and hospice organizations and their volunteers for their generous participation in and cooperation with our research.

Please address correspondence to Marc T. Kiviniemi, Department of Psychology, University of Nebraska-Lincoln, 238 Burnett Hall, Lincoln, NE 68588-0308; e-mail: mkiviniemi2@unl.edu.
} 
1994; Snyder, 1993). Individuals frame their perceptions of various activities in terms of those motives (Cantor, 1990; Pervin, 1989), and this framing determines the outcomes that individuals will use to decide their satisfaction with their behavior (e.g., Emmons, 1986; Little, 1983). Because individuals engage in activities in the service of particular motivations, their satisfaction with those activities is determined by the extent to which they feel that their motivations for engagement have been fulfilled. For example, Clary et al. (1998) found that volunteers' satisfaction with their service was dependent on the fulfillment of the motivations that led them to volunteer. Similarly, Omoto, Snyder, and Martino (2000) have shown that different volunteers are led to service by different motivations and that it is motivationally relevant outcomes that weigh most heavily in determining overall satisfaction (see also Crain, Omoto, \& Snyder, 1998).

\section{THE ROLE OF MULTIPLE MOTIVATIONS}

We now turn to a second key feature each of the hypothetical individuals introduced at the beginning of the article has in common. Each individual acts in an attempt to satisfy not one but multiple motivations. For instance, the returning student is motivated to gain career skills, feel better about herself, and express education-related values. Each motivation is conceptually distinct but she seeks to satisfy all of them through a single pattern of actions.

Existing research, however, has rarely examined this second feature of the situations facing our hypothetical individuals. Although the research reviewed above indicates that individuals' motivations influence their choice of and satisfaction with their behaviors, in this prior research, motivations have typically been examined in relative isolation from one another. Some laboratory research has primed a particular motivation and examined the ways in which the primed motive influences behavior (e.g., Higgins, Lee, Kwon, \& Trope, 1995). In effect, this approach addresses only situations in which one motivation operates at a time. Other research has similarly focused on motives in isolation, either identifying a particular motivational goal as primary for an individual (e.g., Omoto et al., 2000; Sanderson \& Cantor, 1995) or measuring several motivations for each individual (e.g., Clary et al., 1998; Omoto \& Snyder, 1995), but still separately assessing the effects of individual motivations on outcomes. Another way of stating this distinction is that existing research has explored differences in the overall amount of a given motivation but has not examined another potentially important feature- differences in the number of conceptually distinct motivations one has for an activity.

To the extent that an action can be conceptualized in terms of multiple motivations (for discussions, see Neis- ser, 1963; Simon, 1967), it is important to ask what effects striving to achieve multiple motivations through a single activity might have on an individual's outcomes. One possibility is that having more than one motivation for engaging in an activity might enhance satisfaction and fulfillment. In general, individuals possessing more of a given motive are more satisfied and fulfilled by engagement in an activity matched to that motivation (e.g., Clary et al., 1998; Omoto \& Snyder, 1995; Penner \& Finkelstein, 1998). Having many motivations for activity engagement, then, may lead to greater overall motivation and thus to enhanced satisfaction.

Multiple motivations also might have a buffering effect on stress, costs, fulfillment, and satisfaction. When one has multiple motivations and one of those motives is not satisfied, one might be able to fall back on the other motivations in achieving outcomes. In this way, multiple motivations might protect the individual from negative outcomes related to one of the motivations, leading to higher levels of satisfaction than having only a single motivation.

Based on these arguments, we might hypothesize that people with multiple motivations would experience more positive outcomes than those engaging in an activity for only one motivation. However, other research suggests the possibility that multiple motivations might have detrimental effects on outcomes. For example, the interplay of multiple motivations has been studied in research exploring the detrimental effects of introducing an extrinsic motivation for engaging in an activity that already is intrinsically motivated (for reviews of this literature, see Deci \& Ryan, 1985; Kassin \& Lepper, 1984). In a classic study in this domain (Lepper, Greene, \& Nisbett, 1973), children were offered a reward for coloring with magic markers, an activity that they previously had found intrinsically rewarding. After being offered the reward, they showed less interest in coloring. Although this research has sometimes been interpreted as changing motivation from intrinsic to extrinsic, it also can be conceptualized as adding a new, extrinsic motivation to an already intrinsically motivated activity. This causes a decline in the children's inherent satisfaction with and interest in the activity (for multiple motivations interpretations of this study, see Sansone, 1999; Shah \& Kruglanski, 2000).

In a second relevant theory, Kuhl (1984) posited that tendencies toward many different goal-directed actions can exist at any one time and that success at a particular activity involves shielding that action from other goal-directed actions that are competing for attention (see also Atkinson \& Birch, 1970). Having simultaneous multiple motivations might have the potential to be detrimental because as the number of different motivations increases, more alternative goal-directed actions are competing for attention, and 
one must therefore direct more effort toward shielding the current action from other competing goals. However, the idea that multiple motivations will lead to competition for resources is conceptually distinct from the situations we are considering. In Kuhl's theorizing, competing motivations each are related to different actions, whereas in our examples, each of the motivations is associated with the same behavior.

\section{OVERVIEW OF STUDIES}

Because existing theories of motivation and behavior do not directly address the issue of multiply motivated actions, there is a need to empirically examine the question of the consequences of construing actions in terms of multiple motivations. We therefore conducted a series of studies to examine the effects that engaging in an activity in the service of multiple motivations would have on experiences of stress, cost, fulfillment, and satisfaction.

Specifically, we addressed the role of multiple motivations for engaging in volunteer service. Volunteering is by definition an individually chosen behavior that is sustained over time (Snyder, 1993). Because volunteer service is freely and individually chosen, it provides an ideal context in which to explore questions of motivation. The sustained nature of volunteerism allows examination of how motivations influence outcomes over time.

Previous research has documented relations between volunteering motivations and fulfillment and satisfaction. Individuals engage in volunteer service for a variety of different motivations (Clary et al., 1998; Omoto \& Snyder, 1995), and greater amounts of motivation to volunteer are related to greater fulfillment and satisfaction (Omoto \& Snyder, 1995; Penner \& Finkelstein, 1998). In addition, the influence of motivation on fulfillment and satisfaction is particularly strong for those motivations that a given individual feels are most important to him or her (Clary et al., 1998, Study 5; Crain et al., 1998). These studies, however, have all addressed differences in the amount of motivation that individuals have for volunteering. None of these investigations explored the effects of having multiple conceptually distinct motivations for volunteering. The studies reported here directly examine these effects.

The three studies reported here explore the impact that possessing multiple motivations for volunteering has on both negative and positive outcomes associated with engaging in a volunteer activity. The first study explored these outcomes in a longitudinal field study of AIDS volunteers. The second study examined the generalizability of the first study's results by examining the effects of multiple motivations in a longitudinal field study of hospice volunteers. Fi- nally, the third study explored the causal effects of number of motivations on outcomes in a laboratory experiment in which individuals performed a volunteering-related activity.

\section{STUDY 1: AIDS VOLUNTEER LONGITUDINAL STUDY}

In our first study, we sought to examine how the experiences of individuals who had a single motivation for engaging in volunteer service would differ from the experiences of individuals who had multiple motivations for engaging in volunteer service. The motivations leading individuals to engage in volunteer service and the outcomes they experienced related to that service were assessed in a 6-month longitudinal study. We examined particularly the role that the number of motivations individuals reported before beginning volunteer service had in determining their experiences of stress, perceptions of cost, sense of fulfillment, and feelings of satisfaction with volunteer service after having volunteered for several months.

\section{Method}

\section{OVERVIEW}

Prior to beginning training as volunteers, participants reported their motivations for volunteering and provided information about demographic and psychological characteristics (initial questionnaire). After 6 months of volunteer service, stress, cost, fulfillment, and satisfaction were assessed (6-month outcome questionnaire). ${ }^{1}$

\section{PARTICIPANTS}

Participants included 282 individuals (146 women, 136 men; $M$ age $=36.4$ years, $S D=10.7$ years) who completed the 6-month longitudinal study. These participants were drawn from a larger group of 491 participants who completed a volunteer training program at one of three Midwestern AIDS service organizations (a completion rate of $57.4 \%$ ). ${ }^{2}$ All participants were assigned to a "buddy/home helper" program in which they had direct contract with a client with HIV/AIDS and provided the client with both emotional support and day-to-day assistance. Those who completed the study were older and had higher educational levels than noncompleters, and completers had lower expectations for satisfaction with volunteering, all $t \mathrm{~s}(488)>2.30$, all $p \mathrm{~s}$ $<.05$. The two groups did not differ on any other psychological or demographic characteristics. Of importance, the two groups did not differ in likelihood of being singly versus multiply motivated, $\chi 2(1)=1.70, n s$. 
MEASURES

\section{Initial Questionnaire}

Motivations for volunteering. Volunteers reported how important each of five different motivations was to them in making their decision to engage in volunteer service. Motive importance was assessed with a 25-item inventory consisting of five separate subscales (Omoto \& Snyder, 1995). Each subscale consisted of five items rated on a 7-point scale $(1=$ not at all important, 7 = extremely important $)$. The five motivation subscales were Values (e.g., "Because of my personal values, convictions, and beliefs," $\alpha=.74$ ), Understanding (e.g., "To understand AIDS and what it does to people," $\alpha=.80$ ), Personal Development (e.g., "To challenge myself and test my skills," $\alpha=.77$ ), Community Concern (e.g., "Because of my concern and worry about certain communities," $\alpha=.81$ ), and Esteem Enhancement (e.g., "To feel better about myself," $\alpha=.78$ ).

Demographic characteristics. Participants reported their age and gender. Educational background was assessed by asking participants to report their highest education level (ranging from less than high school to advanced study or degree). In addition, participants reported whether they had additional current volunteer roles and whether they had any prior volunteer experience (each question was coded "yes" or "no").

Psychological characteristics. Self-esteem was assessed with 10 items from the Rosenberg (1965) Self-Esteem Scale (e.g., "I feel I have a number of good qualities," where $1=$ strongly disagree and $7=$ strongly agree, $\alpha=.83$ ). Ten items from the UCLA Loneliness Scale (Russell, Peplau, \& Cutrona, 1980) assessed loneliness (e.g., "I lack companionship," where 1 = strongly disagree and 7 = strongly agree, $\alpha=.82$ ). Four items assessed volunteers' beliefs in the efficacy of AIDS volunteers (e.g., "I can have an impact on the course of a person with AIDS's disease," where 1 = strongly disagree and $7=$ strongly agree, $\alpha=.78$ ). Eight items assessed expected satisfaction with volunteer service (e.g., "I expect to feel satisfied by my experience as a buddy/home helper," where $1=$ not at all and $7=$ extremely, $\alpha=.76$ ) and eight items assessed expected costs of volunteer service (e.g., "I expect to feel emotionally drained by my experience as a buddy/home helper," where $1=$ not at all and $7=$ extremely, $\alpha=.71)$.

\section{6-Month Outcomes Questionnaire}

Negative experiences. We examined volunteers' reports of two conceptually distinct negative aspects of their volunteer experiences - the stress they felt from volunteering and their perceptions of the costs of engaging in volunteer service. Volunteers reported on the stress associated with volunteering by indicating their agreement with two statements about volunteering (e.g., "My volunteer work has added a lot of stress to my life," where 1 = strongly disagree and 7 = strongly agree, $r=.42$ ). Perceptions of costs associated with volunteering were assessed using four items about participants' experiences (e.g., "Being an AIDS volunteer takes up too much of my time," $\alpha=.77$ ). Participants indicated their agreement with each statement on a 7-point scale with endpoints of strongly disagree (1) to strongly agree (7).

Positive experiences. We also assessed two distinct positive experiences as a result of volunteer service. Volunteers reported the extent to which each of the motivations assessed in the initial questionnaire had been fulfilled. They reported on the amount of fulfillment of each of 10 outcomes related to their motivations for volunteering (e.g., "My feelings that others need me"; 2 items assessed fulfillment of each of the five motivations; $\alpha$ s range from .82 to $.50)$. Individuals reported whether volunteering increased or decreased each outcome on a 7-point scale $(1=$ volunteering has decreased this a great amount, $7=$ volunteering has increased this a great amount).

The extent to which individuals were satisfied with their motivation-related outcomes was assessed with 13 items corresponding to the motivations assessed in the initial questionnaire (e.g., "The amount I have learned about AIDS and people with AIDS"; 2 to 3 items assessed each motivation; $\alpha$ s range from .79 to .57). Participants indicated their satisfaction with each item on a 7-point scale with endpoints of extremely dissatisfied (1) to extremely satisfied (7).

\section{Defining Multiple Motivations}

To identify singly and multiply motivated individuals, we needed to assess the number of conceptually distinct motivations leading an individual to volunteer. To do this, we examined the means for each participant's five motivation scores from the initial questionnaire. We began by identifying the highest mean motivation score and then compared the means of the other four scale scores to that highest score. Individuals were defined as multiply motivated if at least one additional scale score fell within one scale point of their highest rated motivation scale. Individuals who had no additional motivation scale means within one scale point of the highest were defined as singly motivated. For example, an individual whose highest mean motivation score was Values, with a mean of 5.8, and whose next highest score was Personal Growth, with a mean of 5.1, would be considered multiply motivated because 5.1 is within one scale point of 5.8. By contrast, another individual with the same highest Values mean (5.8) but whose next highest motivation scale score was 4.5 would be considered singly motivated. Of importance, this approach defines multiple motivations independent of the overall amount of motivationa participant with scores of 2.8 and 2.1 would be multiply 
motivated just as would the person with scores of 5.8 and 5.1. Because we were interested in exploring the effect of multiple conceptually distinct motivations independent of the overall amount of motivation, this characteristic is particularly desirable.

It is important to note that this is only one of a number of possible ways of operationalizing the multiple motivations concept and does have the shortcoming of categorizing what is, in some sense, a quasi-continuous variableone can range from one to five motivations for volunteering. Unfortunately, highly unequal cell sizes prevent using this continuous measure of multiple motivations (there were 105 volunteers with one motivation and only 4 volunteers with five motivations). ${ }^{3}$ We examined two potential alternative continuous variable operationalizations. In one, we used the within-subject standard deviation of the five motivation scores as a measure of multiple motivations. As the variance among the scores becomes smaller, the individual is likely to have multiple motivations that are nearly equally important. We also operationalized multiple motivations using the average within-subject difference between scores on each of the five motivation scales (i.e., each of the 10 possible difference scores was computed and the average of those was calculated). As that average difference decreases, the multiply motivated nature of the individual's volunteering increases. Both of these alternative operationalizations correlated highly with the simple dichotomous measure used in the studies, $r \mathrm{~s}(282)=-.574$ and -.572 , respectively, both $p s<.001$. We also examined the volunteer outcome analyses using both alternative operationalizations. Both alternatives produced results that match those reported below. However, given the advantages of the scale-point definition outlined above, and for clarity, we elected to use it as the operationalization of single versus multiple motivations.

\section{Results}

\section{DISTRIBUTION OF SINGLY AND MULTIPLY MOTIVATED VOLUNTEERS}

An initial question of interest involved looking at the distribution of single and multiple motivations in the group of volunteers. Of the 282 volunteers, 105 (37.2\%) were singly motivated, whereas 177 (62.9\%) were multiply motivated. Further breaking down the 177 volunteers in the multiply motivated group, 94 (33.3\% of the overall sample) had two motivations, 55 (19.5\%) had three motivations, 24 (8.5\%) had four motivations, and $4(1.4 \%)$ had five motivations. Thus, being multiply motivated was a common characteristic in our sample.

We examined several demographic and psychological characteristics to see if singly and multiply motivated volunteers differed prior to their volunteer service. Singly and multiply motivated volunteers did not differ on age, self-es- teem, efficacy beliefs, expected satisfaction with volunteer service, or expected costs of volunteering, all $F_{\mathrm{s}}(1,256)<$ $1.96, n s$. Singly motivated volunteers were somewhat more likely to be women, $\chi 2(1)=3.55, p=.06$, and multiply motivated volunteers were somewhat more lonely $(M=1.89$, $S D=0.44)$ than were singly motivated volunteers $(M=1.81$, $S D=0.47), F(1,256)=3.12, p=.08$. Controlling for gender and loneliness in analyses did not change any patterns of results. Taken as a whole, this set of nonsignificant demographic and psychological differences increases our confidence that the distinction between single and multiple motivations is a meaningful feature and not due to other characteristics of our volunteer sample. With this in mind, we next turn to looking at the effects of multiple motivations on outcomes related to volunteer service.

\section{OUTCOMES}

\section{Negative Experiences}

After 6 months of volunteer service, multiply motivated volunteers reported significantly more stress $(M=3.59$, $S D=1.13)$ than did their singly motivated counterparts $(M$ $=3.25, S D=1.03), F(1,280)=6.45, p<.01, \eta 2=.022$, a small effect size (Cohen, 1988). Multiply motivated volunteers also reported significantly higher perceived costs associated with volunteering (multiple $M=2.42, S D=1.22$; single $M=2.09, S D=1.02), F(1,279)=5.23, p<.05, \eta 2=$ .018 , a small effect size.

\section{Positive Experiences}

Motivation fulfillment. We first examined the degree of fulfillment of motivations volunteers believed their volunteer service had provided. Because the fulfillment measures were tied to specific motivations that were differentially important to the volunteer, we created separate fulfillment indices for those motivations that were personally important to the volunteer (i.e., those that were within one scale point of the most highly rated motive) and those that were not as important (i.e., not within one scale point of the most highly rated motive). We next conducted a $2 \times 2$ MANOVA with type of volunteer (singly, multiply motivated) as a between-subjects factor and type of motivation (important, not important) as a within-subjects factor. There was a significant interaction between type of volunteer and type of motivation, $4 F(1,275)=8.77, p<.01, \eta 2=.03$, a small effect size. Follow-up analyses revealed that multiply motivated volunteers experienced less fulfillment of their personally important motives after 6 months of service $(M=$ $5.34, S D=0.62)$ than did singly motivated volunteers $(M=$ $5.71, S D=0.90), F(1,279)=16.16, p<.001, \eta 2=.06$, a medium effect size. However, for motives that were not personally important, there was no difference in fulfill- 
ment for singly $(M=5.22, S D=0.64)$ versus multiply motivated volunteers $(M=5.08, S D=0.61), F(1,277)=$ 3.01 , ns, $\eta 2=.01$. Multiply motivated volunteers experienced lower levels of fulfillment of their motivations only for those motivations that were particularly important to them.

Satisfaction. In addition to assessing motivation fulfillment, we also examined the extent to which volunteers were satisfied with their outcomes. As with the fulfillment measure, we examined differences in satisfaction for included and not-included motivations using the mixed-model MANOVA strategy. There was a significant interaction between the two factors, $F(1,275)=5.49, p<.05, \eta 2=.20$, a large effect size. Follow-up analyses revealed that singly and multiply motivated volunteers differed significantly in satisfaction for those motivationally relevant outcomes that were important to them (single $M=5.60, S D=0.99$; multiple $M=5.23, S D=0.78), F(1,279)=11.88, p<.001, \eta 2$ $=.04$, a small effect size. However, for outcomes that were not personally important, there was no type of volunteer difference (single $M=5.16, S D=0.84$; multiple $M=4.99$, $S D$ $=0.74), F(1,275)=3.21, n s, \eta 2=.01$. As with fulfillment, multiply motivated volunteers reported lower feelings of satisfaction with the outcomes they received from their volunteer service only for outcomes that were particularly important to them.

\section{Amount Versus Number Of Motives}

Our theoretical analysis of the concept of multiple motivations clearly distinguishes the number of conceptually distinct motivations one has for volunteering from the overall amount of "raw" motivation one possesses for volunteering. At a theoretical level, these are distinct constructs, but in practice, they are related in our sample of volunteers. Multiply motivated volunteers report higher overall amounts of motivation (defined as the average of the five motivation scores; $M=4.15, S D=0.98)$ than do singly motivated volunteers $(M=3.62, S D=0.79), t(280)=-4.68, p$ $<.001$.

Because our hypotheses about the effects of multiple motivations all posit that the effect should be due to simply having more than one important motive, it is important to examine whether the differences in outcomes we have observed are actually due to differences in our multiple motivations construct and not due to differences in overall amount of motivation. To examine this, we included a measure of the overall amount of motivation (defined as the average of the five motivation scores) as a covariate in each of the analyses reported above. All of the analyses remained significant after the inclusion of the covariate. ${ }^{5}$

\section{Discussion}

The results of this longitudinal study show a consistent trend-individuals who engaged in volunteer service to satisfy multiple motivations experienced more negative outcomes and less positive outcomes 6 months later than did those individuals who only had one motivation for engaging in volunteer service. This was true for the stress and costs they experienced, the extent to which they felt that their motivations for volunteering were being fulfilled, and the satisfaction they felt with the outcomes resulting from their work. It is also interesting that these differences occur even after controlling for differences in total motivation and occur even though singly and multiply motivated volunteers did not differ in their expectations about satisfaction and costs before beginning volunteer service.

Several factors make the findings of a consistently negative effect of multiple motivations more impressive. First, the research was done in a field setting that, due to the variety of influences operating in the field (e.g., extraneous variables influencing outcomes; Aronson, Ellsworth, Carlsmith, \& Gonzales, 1990), often makes finding effects more difficult (McClelland \& Judd, 1993). Second, the time span between when volunteers reported their motivations (and were thereby categorized as singly or multiply motivated) and the outcome measures was 6 months. The fact that number of motivations influences outcomes 6 months later is striking and implies a strong and robust effect of number of motivations on outcomes. Also, differences in the specificity of the different measures (i.e., the motivations measured are relatively specific, yet the negative outcomes are rather broad) also makes the finding impressive, given that it is usually more difficult to predict outcomes when the predictor and the criterion are at different levels of specificity (Ajzen \& Fishbein, 1977). With this initial set of findings, we were next interested in both confirming the pattern of results observed and in exploring the generalizability of the negative effects of multiple motivations by examining whether effects would replicate in the context of a different type of volunteer service.

\section{STUDY 2: HOSPICE VOLUNTEER LONGITUDINAL STUDY}

Study 2 examined the generalizability of the detrimental effects related to multiple motivations that were found in Study 1. The participants in Study 2 were volunteers for hospice organizations. Hospice volunteers provide services to individuals in the end stages of terminal illnesses. Compared to the sample of volunteers in our first study, these hospice volunteers were working with clients who were much closer to dying. In addition, the hospice volunteers 
included more women ( $78 \%$ of the sample vs. $53 \%$ in Study 1) and more heterosexual individuals (91\% of the sample vs. $50 \%$ in Study 1). Given these differences, obtaining similar results for the hospice volunteers will allow us to further generalize inferences about the multiple motivations phenomena. The same measures used in the AIDS volunteer study were used for the hospice volunteers, allowing direct comparison of the results for the two samples.

\section{Method}

Participants included 146 individuals (115 women, 29 men, 2 did not indicate; $M$ age $=49.86, S D=15.01$ ) who took part in the study. Those completing the study came from an initial group of 207 participants recruited at the beginning of new volunteer training at one of five hospice organizations in the Midwestern and Western United States. ${ }^{6}$ Completers of the study were older and had lower satisfaction expectations than did noncompleters, $t \mathrm{~s}(203)<1.98$, $p \mathrm{~s}$ $<.05$. The two groups did not differ on any other measured characteristics, including, of importance, being singly versus multiply motivated, $\chi 2(1)<1$, ns.

The methods used in this study were nearly identical to those of Study 1. Certain items from the motivations measure were modified to make them relevant for the hospice sample (e.g., "my knowledge of AIDS" became "my knowledge of terminal illness"). Corresponding changes were made to the motivation-specific outcome measures. The initial questionnaire measure of volunteer efficacy similarly was changed to be applicable to hospice volunteers. Otherwise, all measures used were identical to the measures in Study 1. Outcome measures were again collected after 6 months of volunteer service.

\section{Results}

\section{DISTRIBUTION OF SINGLY AND MULTIPLY MOTIVATED VOLUNTEERS}

As with our sample of AIDS volunteers, an initial question concerns how motivations were distributed in the sample of volunteers. The same scale-point categorization used in Study 1 was used to define singly and multiply motivated volunteers. Of the 146 hospice volunteers, 57 (39.0\%) were singly motivated and $89(61.0 \%)$ were multiply motivated. Of the multiply motivated volunteers, $42(28.8 \%$ of the overall sample) had two motivations, $34(23.3 \%)$ had three motivations, $12(8.2 \%)$ had four motivations, and $1(0.7 \%)$ had five motivations. As in Study 1, the majority of these volunteers were multiply motivated.7

\section{EFFECTS ON OUTCOME VARIABLES}

Each outcome analysis reported for the AIDS volunteer sample was repeated for the hospice sample. For negative outcomes, multiply motivated volunteers reported significantly more stress $(M=2.99, S D=1.08)$ than did volunteers with a single motivation $(M=2.50, S D=0.90), F(1$, $142)=7.29, p<.01, \eta 2=.051$, a small effect size (Cohen, 1988). Multiply motivated volunteers also reported significantly higher perceived costs $(M=2.08, S D=1.04)$ than did those volunteers who were singly motivated $(M=1.69$, $S D=0.67), F(1,142)=5.01, p<.05, \eta 2=.037$, a small effect size.

To examine positive outcomes, we again examined differences in fulfillment of motivations that were part of the volunteers' personally important motivations versus those that were relatively unimportant. There was an interaction between type of motivation (important, not important) and type of volunteer (singly, multiply motivated), $F(1,141)=$ $25.59, p<.001, \eta 2=.15$, a large effect size. For important motivations, singly motivated volunteers reported higher fulfillment of motivations $(M=5.86, S D=1.00)$ than did multiply motivated volunteers $(M=5.31, S D=0.79), F(1$, $142)=13.35, p<.001, \eta 2=.09$, a medium effect size. For unimportant motivations, there was no difference in fulfillment (single $M=5.02, S D=0.69$; multiple $M=5.08, S D=$ $0.72), F(1,141)<1, n s, \eta 2=.002$. As in Study 1 , multiply motivated volunteers experienced less fulfillment of personally important motivations. For motivations that were not personally important, singly and multiply motivated volunteers did not differ.

A similar pattern was found for satisfaction with outcomes. There was again a significant interaction between the two factors, $F(1,142)=14.12, p<.001, \eta 2=.09$, a medium effect size. Follow-up analyses revealed that for those motives important to the volunteer, singly motivated volunteers were significantly more satisfied $(M=5.80, S D=1.15)$ than were their multiply motivated counterparts $(M=5.26$, $S D=1.01), F(1,143)=9.16, p<.01, \eta 2=.06$, a medium effect size. For unimportant motivations, there were not differences based on single/multiple status (single $M=5.42$, $S D=1.02$; multiple $M=5.25, S D=0.99), F(1,142)<1, n s$, $\eta 2=.006$. As in Study 1, satisfaction with personally important outcomes was lower for multiply motivated volunteers, whereas satisfaction with outcomes that were not personally important did not differ between singly and multiply motivated volunteers.

Finally, as with the AIDS volunteer study, we wanted to ensure that the observed relationships could not be explained by differences in overall amount of motivation. We again looked at the effects of number of motivations when amount of motivation was controlled. As with the AIDS volunteer study, controlling for amount of motivation did not change the significance of any of the effects reported above (all $p s<.01$; the covariate is significant for fulfillment and satisfaction, both $p \mathrm{~s}<.05$ ). 


\section{Discussion}

As was the case for AIDS volunteers, multiply motivated hospice volunteers experienced higher cost, more stress, less fulfillment of their important motivations, and less satisfaction with important outcomes than did their singly motivated counterparts. Given the differences between the samples and type of volunteer tasks in the two studies, the findings taken together establish more firmly the existence of negative effects associated with multiple motivations.

The longitudinal nature of the first two studies allows for some inferences about causality within the constraints of correlational research studies. Because motivations were measured prior to beginning volunteer service, differences in outcomes did not lead to differences in number of reported motivations, addressing the direction of causality issue. However, the correlational nature of these data still leaves open the question of whether the multiple motivations themselves are causing the differences in satisfaction with outcomes or whether a potential third (unmeasured) variable accounts for the results. To more directly test this causal hypothesis, we created a laboratory analog to volunteer experience and experimentally manipulated whether individuals were engaging in an activity in the service of one or multiple motivations.

\section{STUDY 3: EXPERIMENTAL STUDY OF MULTIPLE MOTIVATIONS AND OUTCOMES}

Study 3 was designed to test the causal hypothesis about the negative effects of multiple motivations using experimentally manipulated motivations. In this laboratory study, individuals were primed to think about volunteer work in terms of either a single or multiple motivations. They then spent 15 minutes stuffing envelopes for a campus environmental organization. Finally, they reported on their perceptions of volunteer service, their enjoyment of the task, and the extent to which different motives had been satisfied through the task. Bringing our exploration of the multiple motivations effect out of the field setting and into the laboratory afforded a number of opportunities for broadening the scope of our inquiry. First, the laboratory is a very different setting from the "real-world" work in clients' homes in which volunteers in both previous studies engaged. Second, motivations were primed rather than having been measured as a pre-existing difference. Finally, the type of volunteer work, stuffing envelopes for an organization, is very different from caring for a person who has a major disease or who is terminally ill but is consistent with the types of tasks that volunteers do in many organizations and for many causes.

\section{Method}

\section{PARTICIPANTS}

The study included 58 introductory psychology students (23 men, 35 women; $M$ age $=19.2$ years) who participated in the study in exchange for course extra credit.

\section{PROCEDURE}

Participants took part in the study individually and were told that the study was designed to look at people's thoughts about engaging in volunteer activities. They were told that they would do a volunteer activity and then would answer some questions about the activity.

\section{Motivation Manipulation}

Prior to engaging in the volunteer activity, participants read a testimonial ostensibly written by another student who actually volunteered for the organization. Reading the testimonial was done under the pretext of "getting in the mindset" of volunteering before doing the envelope stuffing activity. In reality, the testimonial served as the single versus multiple motives manipulation. After a brief introduction, the testimonial consisted of a series of statements in which the student described why he or she volunteered (gender was purposefully made ambiguous). Participants were randomly assigned to read a testimonial in which these statements focused on either values-related motives (e.g., "I'm able to work on a cause I really care about"), self-esteem-related motives (e.g., "I'm able to do a lot of things that make me feel better about myself"), or one of two testimonials focusing on both motives. The two multiple motivation testimonials were identical, except that the order in which the motives were presented was counterbalanced.

\section{Volunteer Activity}

After reading the testimonial, participants spent 15 minutes doing a volunteer activity involving collating materials for a mailing about recycling that ostensibly was being sent to students by a campus environmental organization. Participants were seated in front of a table containing stacks of $9 \times 12$ " manila envelopes, cover letters from the president of the organization, and two flyers about recycling programs. Participants placed a cover letter and one of each of the flyers in an envelope. After 15 minutes of envelope stuffing, participants completed a questionnaire assessing thoughts about the volunteer activity and were then fully debriefed. 


\section{MEASURES}

The final questionnaire assessed participants' responses to the volunteer task and their thoughts about volunteering. A behavioral measure of productivity also was collected.

Volunteering beliefs. Three items assessed participants' beliefs about volunteering. Participants reported whether they felt it was their personal responsibility to volunteer, their perceptions of the importance of volunteering, and their general interest in volunteer work $(1=$ not at all, $7=$ very much/extremely). The mean of these three items was used as a composite beliefs measure $(\alpha=.80)$.

Barriers to volunteering. A second set of items assessed participants' feelings about potential barriers to volunteering. Participants were asked to what extent most people are too busy to volunteer and how stressful they thought volunteering would be ( $1=$ not at all, $7=$ very much/extremely). The mean of these two items formed a composite measure of barriers to volunteering $(r=.47)$.

Motivation satisfaction. Participants reported the extent to which each of three motivations for volunteer servicevalues, esteem enhancement, and knowledge acquisitionwere satisfied through the envelope stuffing task ( $1=$ not being satisfied at all, 7 = being completely satisfied). The mean of these three items formed a measure of motivation satisfaction $(\alpha=.85)$.

Productivity. After the participant left the laboratory, the experimenter counted how many envelopes the participant had stuffed during the 15-minute period. This served as a behavioral measure of productivity.

\section{Results}

The two single-motivation groups did not differ from each other on any outcome measure, all $t \mathrm{~s}<1.96, \mathrm{~ns}$. Similarly, the two multiple-motivation groups did not differ from one another on any outcome measure, all $t \mathrm{~s}<1.96$, $n s$. Therefore, the two single-motivation groups were combined and the two multiple-motivation groups were combined for subsequent analyses. Because lower positive and higher negative outcomes for multiply motivated participants is an a priori hypothesis based on Studies 1 and 2, all analyses are one-tailed.

There was great variability in participants' task productivity $(S D=17.65$ envelopes; range $=80$ envelopes $)$. Productivity did not significantly differ across the four experimental groups, $F(3,55)=1.03$, ns. However, to control for the possibility that productivity might influence participants' responses to the outcome questions, envelope-stuffing productivity was used as a covariate in all reported analyses. $^{8}$
Volunteering beliefs. Participants in the single-motivation conditions reported significantly more positive beliefs about volunteering $(M=5.99, S D=0.87)$ than did those participants in the multiple-motivation conditions $(M=$ $5.56, S D=0.84), F(1,56)=3.74, p<.05, \eta 2=.063$, a medium effect size (Cohen, 1988).

Barriers to volunteering. Participants in the single motivation conditions reported somewhat lower perceived barriers to volunteering $(M=3.28, S D=0.94)$ than did participants in the multiple-motivation conditions $(M=3.71, S D$ $=1.11), F(1,56)=2.47, p=.06, \eta 2=.042$, a small effect size.

Motivation satisfaction. Participants in the single-motivation conditions reported somewhat higher satisfaction of motivations for volunteer service $(M=4.50, S D=1.22)$ than did participants in the multiple-motivation conditions $(M=4.09, S D=1.07), F(1,56)=1.71, p=.10, \eta 2=.03, \mathrm{a}$ small effect size.

\section{Discussion}

As in Studies 1 and 2, individuals with more than one motivation for engaging in an activity experienced less satisfaction of their motivations than did individuals taking part in the activity in the service of a single motivation. In addition, the motivation manipulation had effects on more general attitudes about volunteering and on perceptions of barriers to engaging in volunteer service. These results with experimentally manipulated motivations not only confirm the findings of the two previous studies but provide a causal demonstration of the effects of multiple motivations on volunteer outcomes.

Replicating the outcome effects provides additional evidence for the generality of the multiple motivations effect, especially when some of the characteristics of the laboratory situation are kept in mind. First, participants were college students participating for course extra credit rather than having freely chosen to volunteer. Thus, they almost undoubtedly were less motivated and less committed to the activity than the volunteers in the two field studies. Second, whereas volunteering in the field studies took place over 6 months, participants in the laboratory study engaged in 15 minutes of volunteer work. Thus, multiple motivations did not have much time to exert any negative effects. Third, the detrimental effects of multiple relative to single motivations extended beyond evaluations of the specific activity to include assessments of potential barriers to volunteering and general attitudes toward volunteer work. Thus, we believe that the laboratory analog provides convincing evidence for the generality of the multiple-motivations effect and evidence for the causal role of multiple motivations as a determinant of those effects. 


\section{GENERAL DISCUSSION}

The three studies reported here show a consistent pattern - engaging in a volunteer activity in the service of multiple motivational goals leads people to experience higher levels of stress, greater perceived costs, less fulfillment of their motivations, and lower feelings of satisfaction.

These findings replicate over two different types of realworld volunteer service as well as a volunteer experience in the context of a laboratory experiment. Multiply motivated actions lead to individuals receiving less fulfillment than would be achieved if they only sought satisfaction of one motivation.

\section{Why Might Multiple Motivations Negatively Influence Outcomes?}

The studies reported here provide converging evidence of a phenomenon-multiple motivations increase negative outcomes and inhibit achievement of desired outcomes. Having shown this, we turn to the question of why this phenomenon occurs. What processes might account for the negative impact of multiple motivations?

The analyses in Studies 1 and 2 allow us to rule out some plausible hypotheses. First, it might be the case that multiple motivations influenced outcomes by affecting the expectations individuals had about their activities. Because individuals undertake motivated actions expecting to have certain needs fulfilled, this differential expectations hypothesis would predict that differences in expectations could mediate the multiple-motivations effects. However, our analyses of Time 1 differences between singly and multiply motivated volunteers revealed that the two groups did not differ in terms of their expectations about volunteering, casting doubt on this hypothesis.

A second plausible hypothesis, differential perception, would be that multiple motivations lead to some sort of overall difference in the way that volunteers perceive satisfaction and fulfillment-perhaps multiply motivated individuals have an overall "higher standard" for satisfaction and fulfillment, leading them to perceive that their motivated actions are not meeting their needs as well. Our analyses of satisfaction and fulfillment, however, would suggest that this is not the case. Multiply motivated volunteers perceived lower satisfaction only for those motivations that were particularly important to them. The two groups did not differ on perceptions of fulfillment and satisfaction of motivations that were relatively less important. Looking at the difference another way-that singly motivated volunteers only have more positive outcomes for important motivationsalso rules out the possibility that singly motivated volunteers receive "unexpected benefits" in terms of satisfaction and fulfillment for factors that were initially relatively unimportant to them.

Another possible hypothesis is that there are some motivations that, due to properties of the motivations themselves, inherently conflict with one another (similar to the conflict between intrinsic and extrinsic motivation; Lepper et al., 1973). For example, under this motive conflict hypothesis, it may be the case that volunteers simply cannot simultaneously satisfy an altruistic desire to express concerns for others and a relatively "selfish" desire to develop career skills. Thus, the multiple motivations effect might be driven by volunteers with motives that inherently conflict. Exploratory analyses in the samples from Studies 1 and 2 cast some doubt on this hypothesis. Omoto and Snyder (1995) proposed that the five motivations for volunteering consisted of two larger categories: self-oriented (personal development, esteem enhancement, understanding) and other oriented (values, community concern). Among volunteers who had two important motivations for volunteering, ${ }^{9}$ we examined whether volunteers with nonconflicting motivations (i.e., those with two self- or two other-oriented motivations; $n=45$ ) differed from those with conflicting motivations (i.e., those with one self- and one other-oriented motivation; $n=49$ ). The two groups did not differ on any of our outcome variables, all ts(92) $<1.96$, ns. Although this exploratory analysis casts some doubt on the motive conflict hypothesis, we do consider the analyses to be preliminary and believe that the hypothesis merits further investigation.

We believe that another fruitful area of inquiry into process lies in understanding how individuals conceptualize their motivations and in exploring the cognitive processes by which satisfaction with motivated actions is determined. One hypothesis about the negative effects of multiple motivations would be that differences in the ways that singly and multiply motivated individuals conceptualize and cognitively structure their motivations could influence the satisfaction they ultimately experience as a result of those motivations. For example, singly and multiply motivated volunteers might differ in the complexity of their cognitive structures for motivations. Similar to Linville's (1987) self-complexity construct, one could hypothesize that multiply motivated volunteers might have lower motive complexity - by definition, they have more personally important motivations organized under a single role, whereas singly motivated volunteers have personally important motivations distributed across several different roles (for a similar perspective, see Niedenthal, Setterlund, \& Wherry, 1992). As with Linville's work on self-complexity and buffering of stressful situations, having motives distributed across several different roles could be beneficial when one experiences challenges, setbacks, and stresses related to 
one of the roles. Thus, multiply motivated volunteers might experience greater negative impact as a result of challenges and stresses, which could lead to the negative outcomes found in our research. A direct examination of the cognitive structure of motivations and the role of that structure in mediating effects of multiple motivations could test this idea.

A final possible explanation for the negative effects of multiple motivations would be that the processes involved in perceiving and "computing" satisfaction with motivated actions could lead to differences between singly and multiply motivated volunteers. Because satisfaction with a motivated activity is likely to be determined in light of the motivation or motivations that led to engagement in the activity (e.g., Crain et al., 1998; Omoto \& Snyder, 1995), the motivational goal serves as a sort of "set point" to which subsequent action and outcomes are compared (Carver \& Scheier, 1998). To explain why having multiple motivations undermines the satisfaction and fulfillment that can come from an activity, we need to understand better how individuals conceptualize the comparative set point and how it is that they evaluate outcomes in terms of that comparison.

For example, it could be the case that although individuals are able to identify a given action in terms of multiple motivational goals, they only are able to focus on a single goal at any given time while engaging in the activity (similar to Kuhl's, 1984, theory discussed earlier; see Higgins \& Trope, 1990; Vallacher \& Wegner, 1985, for related perspectives). This multiple-focus hypothesis would predict that inability to focus on multiple goals simultaneously may mean that the multiply motivated individual is simply unable to perceive as much satisfaction of a given motive as is the singly motivated individual because she or he has not focused on that goal consistently throughout the activity. Given the robustness of the multiple motivations phenomenon, we strongly encourage examination of each of these underlying process hypotheses in future research.

\section{Conclusion}

Psychologists have long held that individuals engage in behaviors in the service of various self-relevant goals and that satisfaction with their behaviors is related to the fulfillment of those goals. Our studies highlight the fact that, when considering motivations, one can have "too many of a good thing." Engaging in a given activity in the service of more than one motivation leads to more stress and greater costs, as well as less fulfillment and satisfaction. These findings have important implications for endeavors, such as volunteer service, that rely on individuals' ongoing motivation to engage in an activity. There is a need to both understand more fully the relationship between motivations and satisfaction and to explore how individuals determine their satisfaction with motivation-related actions.

\section{NOTES}

1. Other questionnaires were completed after completing training but prior to beginning service and after 3 months of service. These measures largely concerned the nature of the relationship between the volunteer and the client they were assisting. In addition, the questionnaires from the two time points reported here also contained other measures. Because none of these measures are related to the central concern of this article, they will not be discussed further.

2. Initially, 893 participants were screened for inclusion. These 893 included all individuals beginning a training program at one of the three sites. To meet the inclusion criteria for the current study, participants had to both complete volunteer training and be assigned to a volunteer task working one-on-one in direct contact with a client as a buddy/home helper.

3. We did examine a trichotimous definition of motivation. Three groups were compared: (a) singly motivated volunteers, (b) volunteers with two motivations, and (c) volunteers with three or more motivations. Linear contrast analyses showed that as the number of motivations increased, the negativity of outcomes also increased, all contrast $p \mathrm{~s}<.01$. This is consistent with the results reported in the body of the article.

4. Because this analysis strategy involves fulfillment of motivations that were not important to the individual, the four participants for whom all five motives were important were excluded from this analysis.

5. After covarying amount of motivation, the key significance tests are as follows: stress, $F(1,279)=3.77, p<.05$; cost, $F(1$, $278)=4.35, p<.05$; fulfillment, Type of Motivation $\times$ Type of Volunteer interaction, $F(1,274)=7.58, p<.01$; and satisfaction, $F(1,274)=6.90, p<.01$. The covariate was significant in all models except for cost $(p s<.05)$.

6. As with Study 1, the eligible participants came from a somewhat larger screening group of 294 participants comprising all volunteers beginning training at the hospice organization. Inclusion criteria were identical to those in Study 1.

7. As in Study 1, we also examined the two alternative operationalizations of the multiple motivations constructs. Consistent with Study 1, using the two alternative operationalizations of multiple motivations provided results consistent with those reported using the dichotomous single-multiple analysis strategy. Also as in Study 1, we examined differences in demographic and psychological characteristics. Singly versus multiply motivated volunteers did not differ on any examined characteristics, including, of importance, expectations about costs and satisfaction, both $t \mathrm{~s}(97)<$ $1.3, n s$.

8. Analyses without the covariate did not differ in the pattern of means observed.

9. Considering only those volunteers with two motivations is necessary because volunteers with three or more motivations are much more likely to have "conflicting motives" because, using our definition, there are only two "other-oriented" motivations and, therefore, the only way for three-motive volunteers to have nonconflicting motives is to have all three self-oriented motivations. Four- and five-motive volunteers will always have conflicting motives by this definition; therefore, to avoid any confounding of the number of motivations with the definition of conflicting and nonconflicting motivations, we chose to examine only those volunteers with two motivations. 


\section{REFERENCES}

Ajzen, I., \& Fishbein, M. (1977). Attitude-behavior relations: A theoretical analysis and review of empirical research. Psychological Bulletin, 84, 888-918.

Aronson, E., Ellsworth, P. C., Carlsmith, J. M., \& Gonzales, M. H. (1990). Methods of research in social psychology (2nd ed.). New York: McGraw-Hill.

Atkinson, J. W., \& Birch, D. (1970). The dynamics of action. New York: John Wiley.

Cantor, N. (1990). From thought to behavior: "Having" and "doing" in the study of personality and cognition. American Psychologist, 45, 735-750.

Cantor, N. (1994). Life task problem solving: Situational affordances and personal needs. Personality and Social Psychology Bulletin, 20, 235-243.

Carver, C. S., \& Scheier, M. F. (1998). On the self-regulation of behavior. New York: Cambridge University Press.

Clary, E. G., Snyder, M., Ridge, R. D., Copeland, J., Stukas, A. A., Haugen, J., \& Miene, P. (1998). Understanding and assessing the motivations of volunteers: A functional approach. Journal of Personality and Social Psychology, 74, 1516-1530.

Cohen, J. (1988). Statistical power analysis for the behavioral sciences (2nd ed.). Hillsdale, NJ: Lawrence Erlbaum.

Crain, A. L., Omoto, A. M., \& Snyder, M. (1998, April). What if you can't always get what you want? Testing a functional approach to volunteerism. Paper presented at the annual meetings of the Midwestern Psychological Association, Chicago.

Deci, E. L.,\&Ryan, R.M. (1985). Intrinsic motivation and self-determination in human behavior. New York: Plenum.

Emmons, R. A. (1986). Personal strivings: An approach to personality and subjective well-being. Journal of Personality and Social Psychology, 51, 1058-1068.

Higgins, E. T., Lee, J., Kwon, J., \& Trope, Y. (1995). When combining intrinsic motivations undermines interest: A test of activity engagement theory. Journal of Personality and Social Psychology, 68, 749-767.

Higgins, E. T., \& Trope, Y. (1990). Activity engagement theory: Implications of multiply identifiable input for intrinsic motivation. In E. T. Higgins \& R. M. Sorrentino (Eds.), Handbook of motivation and cognition (Vol. 2, pp. 229-264). New York: Guilford.

Kassin, S. M., \& Lepper, M. R. (1984). Oversufficient and insufficient justification effects: Cognitive and behavioral development. In J. Nicholls (Ed.), Advances in motivation and achievement (Vol. 3). Greenwich, CT: JAI.

Kuhl, J. (1984). Volitional aspects of achievement motivation and learned helplessness: Toward a comprehensive theory of action control. In B. A. Maher \&W. A. Maher (Eds.), Progress in experimental personality research (pp. 99-171). New York: Academic Press.

Lepper, M. R., Greene, D., \& Nisbett, R. E. (1973). Undermining children's intrinsic interest with extrinsic reward: A test of the overjustification hypothesis. Journal of Personality and Social Psychology, 28, 129-137.
Linville, P. W. (1987). Self-complexity as a cognitive buffer against stress-related illness and depression. Journal of Personality and Social Psychology, 52, 663-676.

Little, B. R. (1983). Personal projects: A rationale and methods for investigation. Environment and Behavior, 15, 273-309.

McClelland, G. H., \& Judd, C. M. (1993). Statistical difficulties of detecting interactions and moderator effects. Psychological Bulletin, 114, 376-390.

Neisser, U. (1963). The imitation of man by machine. Science, 139, 193-197.

Niedenthal, P. M., Setterlund, M. B., \& Wherry, M. B. (1992). Possible self-complexity and affective reactions to goal-relevant evaluation. Journal of Personality and Social Psychology, 63, 5-16.

Omoto, A. M., \& Snyder, M. (1995). Sustained helping without obligation: Motivation, longevity of service, and perceived attitude change among AIDS volunteers. Journal of Personality and Social Psychology, 68, 671-686.

Omoto, A. M., Snyder, M., \& Martino, S. C. (2000). Volunteerism and the life course: Investigating age-related agendas for action. Basic and Applied Social Psychology, 22, 181-197.

Penner, L. A., \& Finkelstein, M. A. (1998). Dispositional and structural determinants of volunteerism. Journal of Personality and Social Psychology, 74, 525-537.

Pervin, L. (1989). Goal concepts in personality and social psychology. Hillsdale, NJ: Lawrence Erlbaum.

Rosenberg, M. (1965). Society and the adolescent self-image. Princeton, NJ: Princeton University Press.

Russell, D., Peplau, L. A., \& Cutrona, C. E. (1980). The revised UCLA Loneliness Scale: Concurrent and discriminant validity evidence. Journal of Personality and Social Psychology, $39,472-480$.

Sanderson, C. A., \& Cantor, N. (1995). Social dating goals in late adolescence: Implications for safer sexual activity. Journal of Personality \& Social Psychology, 68, 1121-1134.

Sansone, C. (1999). Introductory comments. Journal of Experimental Social Psychology, 35, 205-208.

Shah, J. Y., \& Kruglanski, A. W. (2000). The structure and substance of intrinsic motivation. In C. Sansone \& J. M. Harakiewicz (Eds.), Intrinsic and extrinsic motivation: The search for optimal motivation and performance (pp. 105-127). San Diego, CA: Academic Press.

Simon, H. A. (1967). Motivational and emotional controls of cognition. Psychological Review, 74, 29-39.

Snyder, M. (1993). Basic research and practical problems: The promise of a "functional" personality and social psychology. Personality and Social Psychology Bulletin, 19, 251-264.

Vallacher, R. R., \& Wegner, D. M. (1985). A theory of action identification. Hillsdale, NJ: Lawrence Erlbaum.

Submitted November 2000; accepted with revisions September 2001. 